\title{
Improvement of Bioremediation Performance for the Degradation of Petroleum Hydrocarbons in Contaminated Sediments
}

\author{
Laura Rocchetti, Francesca Beolchini, Maurizio Ciani, and Antonio Dell'Anno \\ Dipartimento di Scienze della Vita e dell'Ambiente, Università Politecnica delle Marche, Via Brecce Bianche, 60131 Ancona, Italy \\ Correspondence should be addressed to Francesca Beolchini, f.beolchini@univpm.it
}

Received 24 May 2011; Revised 8 August 2011; Accepted 12 August 2011

Academic Editor: Ligia Rodrigues

Copyright (C) 2011 Laura Rocchetti et al. This is an open access article distributed under the Creative Commons Attribution License, which permits unrestricted use, distribution, and reproduction in any medium, provided the original work is properly cited.

Microcosm bioremediation strategies were applied to sediments contaminated with hydrocarbons. Experiments were performed in aerobic conditions in a single-step treatment and in a two-step anaerobic-aerobic treatment. In aerobic conditions, either inorganic nutrients or composts were added to the microcosms, while, in the first anaerobic phase of the two-step experiment, acetate and/or allochthonous sulfate-reducing bacteria were used. After the treatment under anaerobic conditions, samples were exposed to aerobic conditions in the presence of compost. In the aerobic treatments, $81 \%$ hydrocarbon biodegradation was observed after 43 days in the presence of inorganic nutrients. In aerobic conditions in the presence of mature compost, hydrocarbon biodegradation was $51 \%$ after 43 days of treatment, whereas it was $47 \%$ after 21 days with fresh compost. The two-step experiment allowed us to obtain a hydrocarbon degradation of $91 \%$, after a first anaerobic step with an inoculum of sulfate-reducing prokaryotes.

\section{Introduction}

Marine sediments represent the principal sink for a wide variety of organic contaminants, and the materials that are periodically dredged from harbors potentially contain many contaminants. A number of technologies have been developed aimed at the reduction of the contamination present in soils and subsequently have also been applied to sediments. Among these, biological treatments are having more importance in the last years, mainly because of the low environmental impact, the costs (in general cheaper than other cleanup technologies), the capability to destroy organic contaminants, and the possibility of beneficial use of treated sediments [1]. In fact, dredged material can be used for beneficial utilizations, as remediation/creation of upland habitat, beach nourishment, or building materials [2].

Bioremediation technologies may consist in stimulation of autochthonous microorganisms (adding nutrients, amendments, increasing oxygen concentration) [3-5] and introducing allochthonous degrading prokaryotes [6-8]. One of the advantages of using natural microorganisms is that they could produce several compounds, such as biosurfactants, useful for the acceleration of hydrocarbon degradation processes $[9,10]$. These compounds are made up of a hydrophilic part and a hydrophobic part, and this structure allows them to increase the bioavailability of different compounds, such as hydrocarbons $[11,12]$.

The present work deals with two bioremediation studies to reclaim dredged materials contaminated with petroleum hydrocarbons. Laboratory microcosms were carried out both in a single-step treatment in aerobic conditions and in a two-step anaerobic-aerobic treatment. In the single-step experiments in aerobic conditions, inorganic nutrients and compost have been tested as amendments. Nutrients are known to stimulate microorganisms adapted to live in chronically polluted environments, like harbors $[13,14]$. Compost can support diverse assemblages of microorganisms, acting as a nutrient source, thereby improving the environmental conditions of a contaminated matrix for indigenous or introduced microorganisms [15]. Furthermore, organic matter contained in the compost can strongly influence 


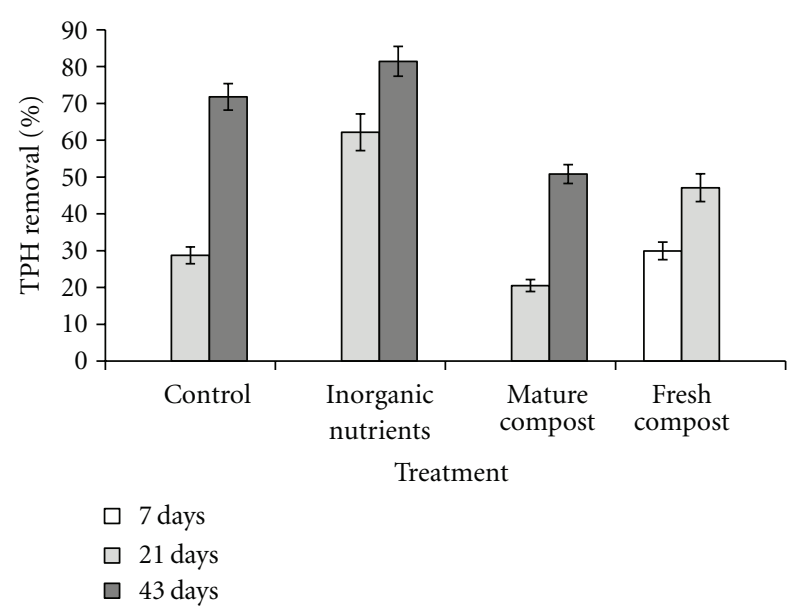

Figure 1: Percentages of TPH removal in the single-step experiments in aerobic conditions after 7, 21, and 43 days of treatment.

sorption/desorption processes of hydrophobic organic contaminants [16]. Nevertheless, most studies concern the application of compost for soil treatment, and it has not been widely applied for sediment bioremediation [15]. The two-step sequential anaerobic-aerobic treatment for sediments is not common in the scientific literature. In fact, traditional bioremediation technologies are usually performed in a single step, either under anaerobic conditions $[17,18]$, where the microorganisms which play the most important role are sulfate-reducing prokaryotes [19], or in aerobic conditions, often using inorganic nutrients to stimulate autochthonous prokaryotes [20-22]. For example, Beolchini et al. [23] carried out bioremediation experiments in aerobic conditions, using inorganic nutrients and sand to stimulate the metabolism of the microbial community and hydrocarbon biodegradation. Hydrocarbon degradation coupled to sulfate reduction seems to be the most relevant process under anaerobic conditions [24]. Therefore, in the anaerobic pretreatment, a consortium of sulfate-reducing prokaryotes was used according to the factorial plan used for this work in order to enhance hydrocarbon removal: an amendment of sodium acetate under anaerobic conditions was also tested as a carbon source $[25,26]$ and as electron donor to stimulate sulfate-reducing prokaryotes [27]. In fact, most sulfate-reducing microorganisms are unable to degrade high-molecular-mass compounds and depend on fermentation products, such as acetate, for their metabolism [28].

\section{Materials and Methods}

2.1. Sampling and Sediment Characterization. Sediment was collected from the harbor of Ancona (Italy, Adriatic Sea) by means of a Van Veen grab. Sediment was characterized by reducing conditions and appeared black, with a strong smell of hydrogen sulfide. Laboratory analyses were performed to determine water content, grain size, total organic matter,

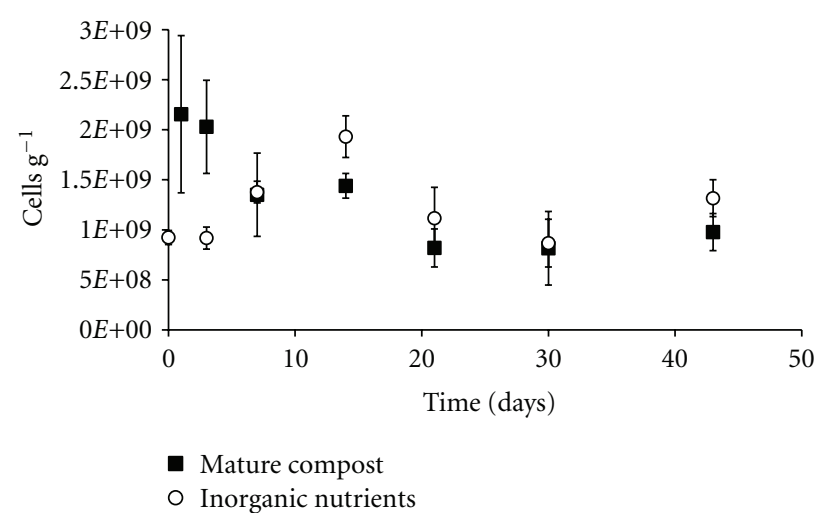

FIgURE 2: Microbial abundances in the microcosms incubated in aerobic conditions, amended with mature compost and inorganic nutrients. Error bars indicate standard deviation of the means.

TABLe 1: Factors and levels in the anaerobic pretreatments of the two-step anaerobic-aerobic treatment.

\begin{tabular}{lcc}
\hline Factors & \multicolumn{2}{c}{ Levels } \\
\hline Sodium acetate $(1 \% \mathrm{w} / \mathrm{v})$ & no & yes \\
Anaerobic step length $($ days $)$ & 30 & 60 \\
Sulfate-reducing prokaryotes $(10 \% \mathrm{v} / \mathrm{v})$ & no & yes \\
\hline
\end{tabular}

TABLE 2: Operating conditions in the anaerobic pretreatments (Table 1 shows factors and levels).

\begin{tabular}{lccc}
\hline Treatments & Sodium acetate & $\begin{array}{c}\text { Treatment length } \\
\text { (days) }\end{array}$ & $\begin{array}{c}\text { Sulfate reducing } \\
\text { prokaryotes }\end{array}$ \\
\hline 1 & no & 30 & no \\
2 & yes & 30 & no \\
3 & no & 60 & no \\
4 & yes & 60 & no \\
5 & no & 30 & yes \\
6 & yes & 30 & yes \\
7 & no & 60 & yes \\
8 & yes & 60 & yes \\
\hline
\end{tabular}

microbial abundance, redox potential, microbial oxygen consumption, and total hydrocarbon content.

Water content of $58 \%$ was calculated as the difference between wet and dry weight and expressed as percentage. Total organic matter (TOM) was $53.2 \mathrm{mg} \mathrm{g}^{-1}$ (dry sediment). TOM was determined as the difference between dry weight $\left(60^{\circ} \mathrm{C}, 24 \mathrm{~h}\right)$ of the sediment and weight of the residue after combustion for $2 \mathrm{~h}$ at $450^{\circ} \mathrm{C}$. Sediment samples were pretreated with an excess of $10 \% \mathrm{HCl}(\mathrm{v} / \mathrm{v})$ to remove carbonates.

Grain size was determined by sieving technique, which revealed that the sediment was largely dominated by the siltclay fraction (i.e., $>95 \%$ of the particles were $<63 \mu \mathrm{m}$ ).

2.2. Laboratory Microcosm Experiments. Experiments were performed in aerobic conditions and in two-step anaerobicaerobic conditions. Aerobic microcosm experiments were 


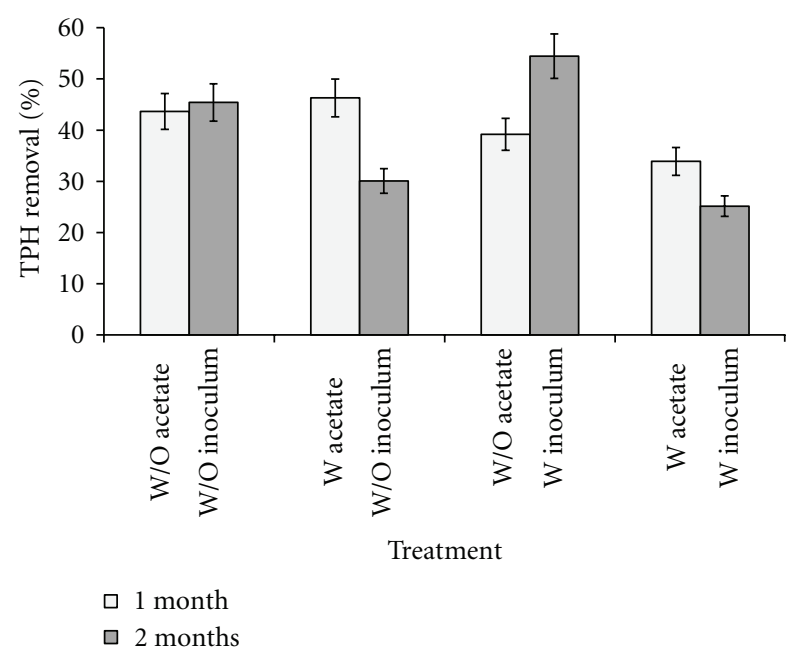

FIGURE 3: TPH removal in the anaerobic pretreatments in the presence $(\mathrm{W})$ and absence $(\mathrm{W} / \mathrm{O})$ of sodium acetate and sulfatereducing prokaryotes.

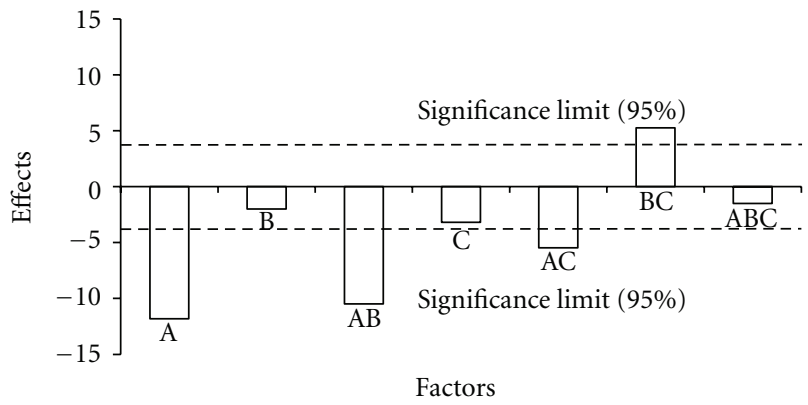

Figure 4: Main effects and interactions in the anaerobic experiments (A: sodium acetate; B: treatment time; C: inoculum of sulfate-reducing prokaryotes; operating conditions in Table 2).

carried out in $250 \mathrm{~mL}$ flasks with sediment $(10 \% \mathrm{w} / \mathrm{v})$ suspended in $0.9 \% \mathrm{NaCl}$ solution to a final volume of $100 \mathrm{~mL}$. Four different experimental flasks were set up: (i) control, containing sediment and saline solution; (ii) inorganic nutrients, with $\mathrm{K}_{2} \mathrm{HPO}_{4}$ and $\left(\mathrm{NH}_{4}\right)_{2} \mathrm{SO}_{4}$ in a molar ratio carbon: nitrogen : phosphorus equal to $100: 10: 1$, on the basis of total organic matter present in the sediment; (iii) $5 \% \mathrm{w} / \mathrm{v}$ mature compost aged 90 days, produced from the organic fraction of municipal solid waste; (iv) $5 \% \mathrm{w} / \mathrm{v}$ fresh compost, aged 30 days, produced from the organic fraction of municipal solid waste. Compost composition was available only for mature compost (total organic carbon $31.3 \pm 2.2 \%$, total nitrogen $2.1 \pm 0.1 \%$, and total phosphorus $1.4 \pm 0.5 \%$ ), because it is a marketable good, while, for fresh compost, not available in the market, the composition was unknown. Microcosms were maintained in aerobic conditions in a shaking incubator at a speed of $180 \mathrm{rpm}$ at $35^{\circ} \mathrm{C}$ for 43 days. Samples were periodically collected for total petroleum hydrocarbon (TPH) analyses and for the determination of prokaryotic abundance. In these experiments composts at two different stages of maturation were selected in order to provide insights on the response of prokaryotic growth and hydrocarbon degradation. Conversely, for the two-step anaerobic-aerobic treatments, only mature compost was used to potentially mimic a full-scale application, being such kind of compost easily found in the market.

For the two-step anaerobic-aerobic treatments, anaerobic microcosm experiments were maintained in the dark at room temperature, in $250 \mathrm{~mL}$ flasks containing $10 \%(\mathrm{w} / \mathrm{v})$ sediment and synthetic seawater with a salinity of $35 \%$ (final volume $100 \mathrm{~mL}$ ). The operating conditions of the anaerobic step have been chosen according to a complete factorial plan with 3 factors and 2 levels. The factors were (i) amendment with sodium acetate $(1 \% \mathrm{w} / \mathrm{v})$, (ii) anaerobic treatment length, and (iii) inoculum of a consortium of sulfate-reducing prokaryotes $(10 \% \mathrm{v} / \mathrm{v})$. Factors and levels are shown in Table 1, while Table 2 displays in detail the operating conditions of each treatment. Sulfate-reducing prokaryotes were selected from environmental samples and provided by Professor Groudev's group, of the University of Mining and Geology "Saint Ivan Rilski", Sofia (Bulgaria), and were grown in their ideal medium. Redox potential determinations were performed to assure the presence of anaerobic conditions (Eh values were always lower than $-200 \mathrm{mV}$; data not shown), and samples were collected for the determination of total microbial abundance and TPH concentration.

Sediments pretreated for 30 and 60 days under anaerobic conditions were then incubated in aerobic conditions with mature compost (aged 90 days). At the end of each anaerobic step, sediment was centrifuged at $3000 \mathrm{rpm}$ for 5 minutes and washed with deionized water to eliminate salts and metabolic products from the sediment. Mature compost $(0.5 \%, \mathrm{w} / \mathrm{v})$ was added to $100 \mathrm{~mL}$ flasks containing the pretreated sediment ( $5 \% \mathrm{w} / \mathrm{v}$ in $0.9 \% \mathrm{NaCl}$ solution, final volume $100 \mathrm{~mL}$ ). These microcosms were incubated in aerobic conditions for 1 month in a shaker at $35^{\circ} \mathrm{C}$. Microbial abundance, oxygen concentration, and total petroleum hydrocarbons were periodically determined.

\subsection{Extraction and Determination of Total Petroleum Hydro-} carbons (TPHs). TPH extraction was done in accordance with method 3550C EPA (US Environmental Protection Agency), and the extract was analyzed by gas chromatography. For TPH extraction $\mathrm{Na}_{2} \mathrm{SO}_{4}$ and a solution of $\mathrm{CH}_{2} \mathrm{Cl}_{2}: \mathrm{CH}_{3} \mathrm{COCH}_{3}(1: 1, \mathrm{v} / \mathrm{v})$ were added to dry sediment and then sonicated for 2 minutes. Samples were put on a shaker at $150 \mathrm{rpm}$ for 30 minutes, centrifuged for 10 minutes at $5000 \mathrm{rpm}$, and passed through a filter (Type GS for clay, $0.22 \mu \mathrm{m})$. Sediments were washed with $\mathrm{CH}_{2} \mathrm{Cl}_{2}$, the solvent was volatilized, and the extract was resuspended with the extraction solution before the analysis. TPH concentration was determined with a Shimadzu GC 2014 chromatograph with a flame ionization detector $\left(\mathrm{FID}\right.$, at $\left.300^{\circ} \mathrm{C}\right)$ injecting $1 \mu \mathrm{L}$ of sample. An Alltech ECONO-CAP EC-5 $30 \mathrm{~m}$ long X $0.32 \mu \mathrm{m}$-inner diameter $(0.25 \mu \mathrm{m}$ film $)$ capillary column was used for hydrocarbon separation, with nitrogen as carrier gas at a flow rate of $3.96 \mathrm{~mL} \mathrm{~min}{ }^{-1}$. The temperature program was set as follows: hold for 2 minutes at $40^{\circ} \mathrm{C}$, ramp to $300^{\circ} \mathrm{C}$ 


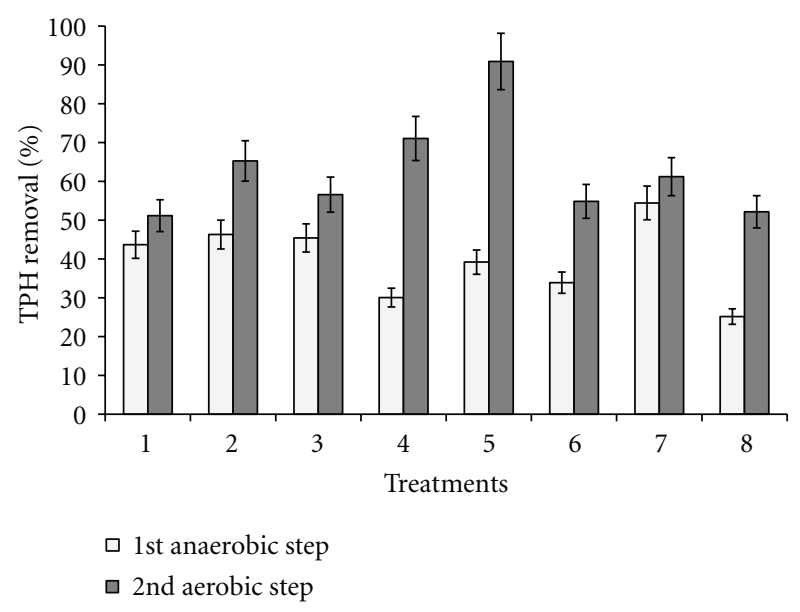

FIgURE 5: TPH removal in the two-step experiment in function of the operating conditions used in the anaerobic pretreatment (see Table 2).

at $8^{\circ} \mathrm{C} \mathrm{min}{ }^{-1}$, and hold for 10 minutes at $300^{\circ} \mathrm{C}$. Analyses were performed in triplicate. Harbor sediment had an initial $\mathrm{TPH}$ content of $1500 \mathrm{ppm}$.

2.4. Total Prokaryotic Counts. Total prokaryotic counts were determined using acridine orange staining according to standard protocols [29]. Sediment subsamples were fixed with prefiltered $(0.2 \mu \mathrm{m}$ pore size $)$ and buffered $\left(\mathrm{Na}_{2} \mathrm{~B}_{4} \mathrm{O}_{7} \cdot 10 \mathrm{H}_{2} \mathrm{O}\right) \quad 2 \%$ formaldehyde. Prokaryotes were detached from the sediment by using tetrasodium pyrophosphate (final concentration: $5 \mathrm{mM}$ ), then subsamples were sonicated three times to increase the extraction efficiency (Branson Sonifier 2200; 60 W for 1 minute) and diluted 100 times. Sediment subsamples were stained for 5 minutes with $0.025 \%$ acridine orange and were filtered on black Nuclepore polycarbonate $0.2 \mu \mathrm{m}$ pore size filters. Filters were washed twice with sterilized Milli Q water and were mounted on microscope slides. Filters were observed at a magnification of 1000x with an epifluorescence microscopy (Zeiss Axioskop 2 ). For each slide at least 10 randomly selected microscope fields were observed and at minimum 200 cells were counted per filter. Total prokaryotic abundance was normalized to dry weight of sediment after desiccation $\left(60^{\circ} \mathrm{C}, 24 \mathrm{~h}\right)$. All counts were replicated at least twice.

2.5. Oxygen Demand. The determination of oxygen demand after $20 \mathrm{~h}$ (OD20) was carried out following a standard protocol with some modifications [30].

\section{Results and Discussion}

3.1. Single-Step Experiment in Aerobic Conditions. It is known that aerobic metabolism is faster than anaerobic metabolism [31]. The common use of aerobic bioremediation methods for sediment decontamination is due to historical observations that microorganisms use oxygenincorporating enzymes to initiate attack on hydrocarbons
[18]. In this work we tested the effectiveness of different biological treatments aimed at the reduction of the contamination associated with sediments. Figure 1 shows hydrocarbon degradation in aerobic conditions during the single-step experiment, using inorganic nutrients and compost at two different ages (fresh compost: 30 days and mature compost: 90 days). The highest removal of TPHs was observed in microcosms where biostimulation was performed in the presence of inorganic nutrients, achieving a hydrocarbon degradation of $62 \%$ after 21 days (compared to $29 \%$ in the control treatment) and $81 \%$ after 43 days (72\% in the control). These results suggest that inorganic nutrient addition increased hydrocarbon biodegradation kinetics especially in the first weeks of the treatments. Nevertheless hydrocarbon removal for a longer length of treatment became similar to natural attenuation processes $[7,8,32]$. These results are consistent with previous findings, based on empirical models which highlighted fast rates of hydrocarbon degradation during the early phase of bioremediation followed by slower rates with increasing time [23]. In the presence of mature compost TPH degradation was $21 \%$ and $51 \%$, respectively, after 21 and 43 days of treatment (Figure 1). On the other hand, TPH degradation was faster in the presence of fresh compost. In fact, a TPH removal of $47 \%$ was observed after 21 days of treatment, significantly higher than the one achieved with mature compost. This fact could be explained by the presence of more bioavailable organic carbon in fresh compost than in the mature compost, which would promote sorption of hydrophobic contaminants and also provide a source of carbon for microorganisms [33]. In addition, the presence of fresh compost could have allowed microorganisms to increase their metabolic activity directed to the degradation of organic compounds, resulting in the production of extracellular enzymes and biosurfactants.

The presence of inorganic nutrients increased hydrocarbon biodegradation to a major extent when compared to systems amended with mature compost. However, such an effect was evident on microbial growth rates only in the first phase of the experiments whereas after ca. 3 weeks no major differences between the two treatments were observed (Figure 2). These findings suggest that the potential effect of bioaugmentation of compost is unlikely to occur because of the difficulty of adaptation and competitive interactions of allochthonous microorganisms with autochthonous microorganisms under the conditions investigated in the study [32].

The oxygen demands in the sediments followed similar temporal patterns of prokaryotic abundances and showed major differences between systems amended with inorganic nutrients and those containing mature compost only at the beginning of the experiments (values of OD20 were 198.3 and $242.9 \mathrm{mg} \mathrm{O}_{2} \mathrm{~L}^{-1} \mathrm{~min}^{-1}$ with inorganic nutrients and mature compost, resp.). With increasing incubation time differences of the oxygen demands were less pronounced ( 101.9 versus $85.8 \mathrm{mg} \mathrm{O}_{2} \mathrm{~L}^{-1} \mathrm{~min}^{-1}$ on day 21 and 96.0 versus $76.2 \mathrm{mg} \mathrm{O}_{2} \mathrm{~L}^{-1} \mathrm{~min}^{-1}$ on day 43 , with inorganic nutrients and mature compost, resp.). These results indicate that an extra carbon source added to the sediments has a similar effect on respiration and growth of prokaryotic assemblages 


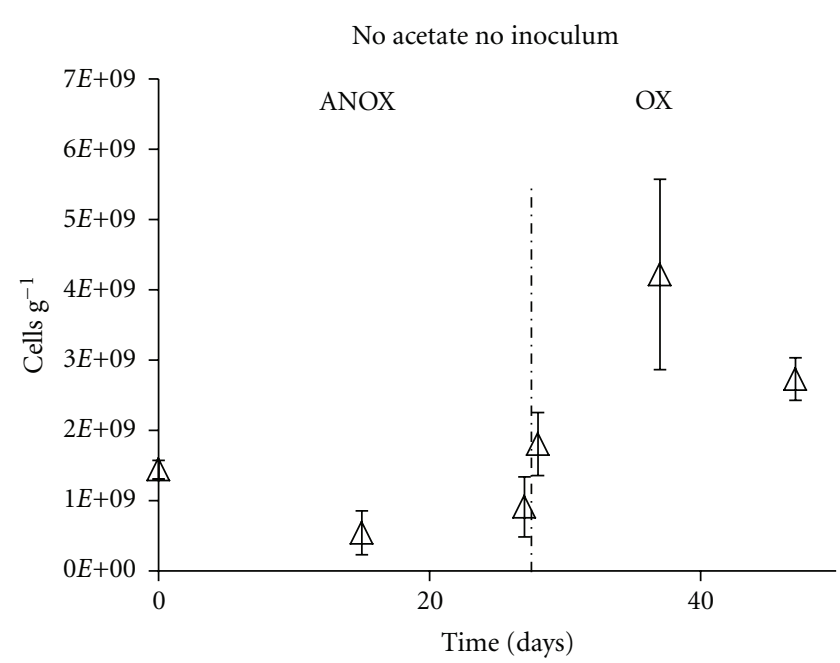

(a)

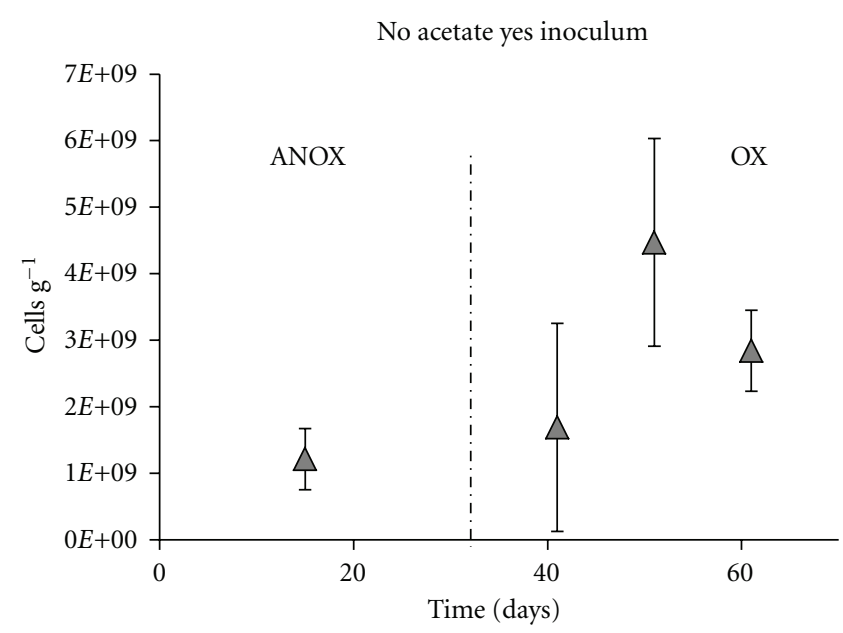

(c)

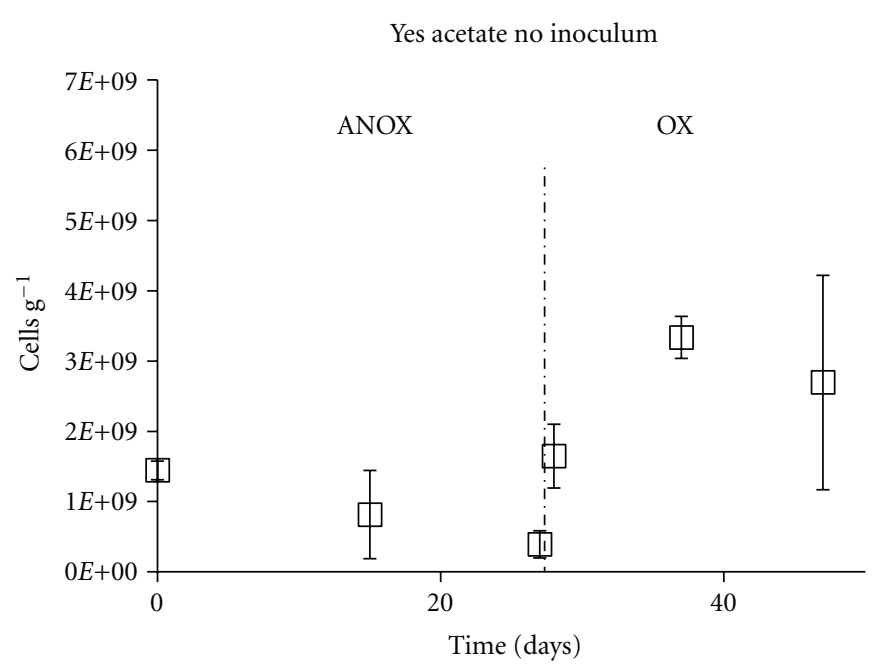

(b)

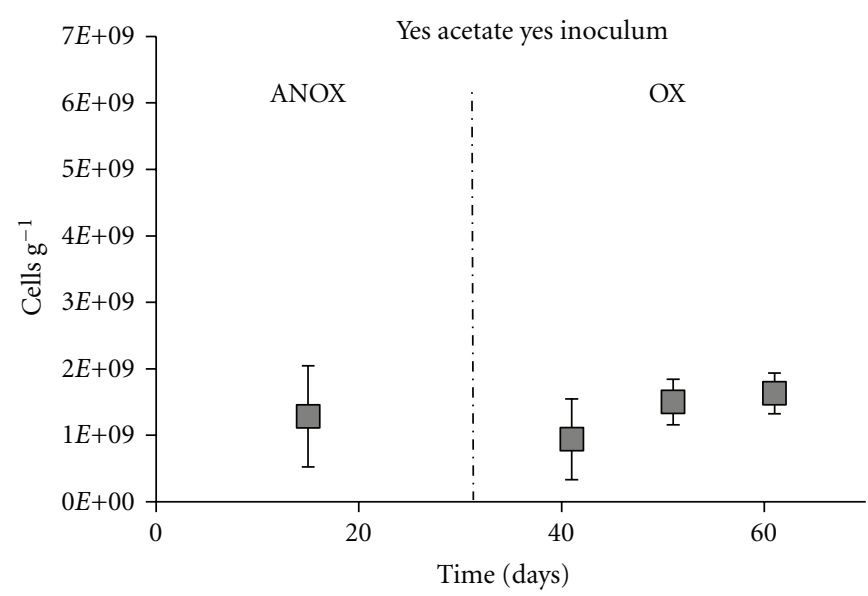

(d)

Figure 6: Microbial abundances in the two-step treatment (one month under anaerobic conditions). In each chart, the left part is referred to the anaerobic pretreatment (ANOX), and the right part to the aerobic treatment (OX). The operating conditions of the anaerobic pretreatment are specified in the legend.

compared with nutrient addition but determines a lower biodegradation performance of hydrocarbons. Therefore, in such conditions prokaryotic metabolic processes appear to be mainly oriented toward the degradation of other organic substrates rather than hydrocarbons.

3.2. Two-Step Anaerobic-Aerobic Experiment. Aerobic treatments may lead to incomplete degradation of contaminants with the production of potentially toxic products [34]. Anaerobic conditions would also allow microorganisms to degrade recalcitrant compounds, such as polycyclic aromatic hydrocarbons [35]. Nevertheless under anaerobic conditions the rate and extent of hydrocarbon biodegradation is usually lower than in aerobic processes [36]. Furthermore it is known that BTEX compounds (i.e., benzene, toluene, ethylbenzene, and xylenes) are biodegradable under anaerobic conditions, and recently it has become apparent that also aliphatic hydrocarbon degradation takes place under anaerobic conditions [37]. According to this scenario, a twostep anaerobic-aerobic treatment has been investigated in the present work, hypothesizing that the anaerobic step would favor the complete degradation of organic contaminants. Table 1 shows factors and levels investigated in the anaerobic pretreatment, whereas Table 2 presents operating conditions of each experiment. Sodium acetate was used to stimulate prokaryotes that can use it as a carbon source [26] and as electron donor [27]. Where specified, a consortium of allochthonous sulfate-reducing prokaryotes was added to microcosms to enhance hydrocarbon biodegradation processes.

3.2.1. First Step: Anaerobic Conditions. Figure 3 shows TPH removal in the microcosms under anaerobic conditions. The highest TPH removal was achieved at the end of the experiment in the presence of sulfate-reducing prokaryotes (54\% degradation, after 60 days of treatment). A TPH 
removal relatively high $(45 \%)$ was also obtained in the control test (without the inoculum of prokaryotes and the acetate amendment) after 60 days under anaerobic conditions. The presence of sodium acetate seems to have a negative effect on hydrocarbon biodegradation in all the investigated conditions, and the lowest TPH removal was found in microcosms simultaneously containing sulfatereducing prokaryotes and sodium acetate. In the presence of acetate, hydrocarbon concentrations increased with increasing incubation time. Such an increase is difficult to explain since no petroleum hydrocarbons were added, but it is likely due to the presence of aliphatic hydrocarbons produced by microbial metabolism, which cannot be discriminated using the present analytical techniques. The results reported in Figure 3 have been elaborated by an analysis of variance (ANOVA) in order to have a better understanding on the main effects and interactions [38]. The ANOVA showed the following remarks (Figure 4).

(i) A negative effect of factor A (sodium acetate, significance $100 \%$ ) confirmed that TPH biodegradation decreased in the presence of sodium acetate. This behavior might be due to a selective use by microorganisms of sodium acetate rather than TPH as carbon source $[25,26]$.

(ii) A negative effect of interaction $\mathrm{AB}$ (A: sodium acetate, B: time, significance 99\%) means that, changing the level of time (i.e., longer length of the experiments), the negative effect due to sodium acetate decreased. When sodium acetate started to be a limiting carbon source during the course of experiments, TPHs were then used as carbon source.

(iii) A negative effect of interaction AC (A: sodium acetate, C: inoculum, significance $98 \%)$ represents a reduction of the negative effect by sodium acetate amendment in the presence of the prokaryotic inoculum. This might be due to a consumption of sodium acetate in the presence of the allochthonous prokaryotes [39].

(iv) A positive effect of interaction $\mathrm{BC}$ (B: time, C: inoculum, significance 98\%) indicates that the presence of a sulfate-reducing consortium significantly increased TPH degradation only for a longer period of treatment in anaerobic conditions (60 days) [39].

3.2.2. Second Step: Aerobic Conditions. After the anaerobic pretreatment, microcosms were incubated in aerobic conditions for 1 month, with a mature compost amendment. Figure 5 shows TPH biodegradation during the aerobic stage of the two-step experiment. As a comparison, the results of the only anaerobic pretreatments, previously reported in Figure 3, are also shown. The highest TPH removal, equal to $91 \%$, was obtained at the end of the aerobic step (30 days) after a pretreatment of 30 days in anaerobic conditions, with an inoculum of sulfate-reducing prokaryotes and in the absence of an acetate amendment (treatment 5 in Table 2). In all aerobic treatments, an increase in $\mathrm{TPH}$ biodegradation was achieved compared to the respective anaerobic pretreatment. In addition, comparing these results with those achieved in the single-step treatment in aerobic conditions with compost at the same age, it can be highlighted that the anaerobic pretreatment had a significant positive effect on hydrocarbon biodegradation. Also in this case an ANOVA was performed to have a better insight of the obtained results. The analysis suggested the following remarks.

(i) Acetate (factor A) seems not to have a significant effect; therefore, the anaerobic pretreatment should have been performed without acetate amendment, with the advantage of cost process saving.

(ii) A negative effect of the interaction AC (A: acetate, C: inoculum, $98 \%$ significance) shows that in the presence of the allochthonous microbial consortium under anaerobic conditions acetate displays a negative effect on TPH removal also in two-step treatment, as already seen in the treatment performed only in anaerobic conditions. This could be due to an inhibition of the activity of sulfate-reducing prokaryotes towards recalcitrant compounds because of the presence of acetate, preferentially used as a carbon source [26].

Microbial abundances determined in the second step in aerobic conditions generally showed an increasing trend during the first 10 days of aerobic treatment (Figure 6 reports the prokaryotic abundances in the microcosms incubated for 30 days under anaerobic conditions; data referring to microcosms incubated for 60 days under anaerobic conditions were similar and are not shown here), with values ranging from $1 \cdot 10^{9}$ cells $\mathrm{g}^{-1}$ to $4 \cdot 10^{9}$ cells $\mathrm{g}^{-1}$. Oxygen consumption at the end of the aerobic phase following a 1month anaerobic step was higher in microcosms containing sodium acetate, both with (OD20 equal to 94.8 and $71.0 \mathrm{mg} \mathrm{O}_{2} \mathrm{~L}^{-1} \mathrm{~min}^{-1}$ with and without acetate, resp.) and without (93.1 and $84.1 \mathrm{mg} \mathrm{O}_{2} \mathrm{~L}^{-1} \mathrm{~min}^{-1}$ with and without acetate, resp.) sulfate reducing prokaryotes.

\section{Conclusions}

The present work deals with a bioremediation study aimed at reclaiming sediments contaminated with petroleum hydrocarbons. In the single-step treatment in aerobic conditions, inorganic nutrients resulted to be more effective in hydrocarbon degradation than compost, in the investigated conditions, and the age of compost also resulted to be an important operating parameter for TPH biodegradation. In fact in the presence of fresh compost (aged 30 days) $\mathrm{TPH}$ biodegradation was higher than with mature compost (aged 90 days). The two-step sequential anaerobicaerobic treatment was the most effective for hydrocarbon degradation (about 90\%), with a significant increase in the effectiveness of TPH bioremediation, compared to the single-step treatments, both in aerobic and under anaerobic conditions. The present study gives an insight on the applied research for eco-friendly technologies for the treatment 
and reclamation of petroleum hydrocarbon-contaminated sediments.

\section{Acknowledgments}

This study was carried out in the frame of a research project supported by Istituto Superiore per la Ricerca e Protezione Ambientale (ISPRA). Dr. Manuela Taccari is acknowledged for support with oxygen demand analysis and chromatographic analysis, Dr. Cristiano Casucci for hydrocarbon extraction, and Dr. Federico Valentini (Gesenu S.p.A) for providing compost.

\section{References}

[1] W. H. Rulkens and H. Bruning, "cleanup technologies for dredged fine sediments: review and future challenges," in Remediation of Contaminated Sediments-2005: Finding Achievable Risk Reduction Solutions, R. F. Olfenbuttel and P. J. White, Eds., p. C6-01, Battelle Press, Columbus, Ohio, USA, 2005, Proceedings of the third international conference on remediation of contaminated sediments (New Orleans, La, USA; January, 2005).

[2] D. J. Yozzo, P. Wilber, and R. J. Will, "Beneficial use of dredged material for habitat creation, enhancement, and restoration in New York-New Jersey Harbor," Journal of Environmental Management, vol. 73, no. 1, pp. 39-52, 2004.

[3] N. Vasudevan and P. Rajaram, "Bioremediation of oil sludgecontaminated soil," Environment International, vol. 26, no. 56, pp. 409-411, 2001.

[4] L. Molina-Barahona, R. Rodríguez-Vázquez, M. HernándezVelasco et al., "Diesel removal from contaminated soils by biostimulation and supplementation with crop residues," Applied Soil Ecology, vol. 27, no. 2, pp. 165-175, 2004.

[5] K. Das and A. K. Mukherjee, "Crude petroleum-oil biodegradation efficiency of Bacillus subtilis and Pseudomonas aeruginosa strains isolated from a petroleum-oil contaminated soil from North-East India," Bioresource Technology, vol. 98, no. 7, pp. 1339-1345, 2007.

[6] R. M. Atlas, "Microbial hydrocarbon degradationbioremediation of oil spills," Journal of Chemical Technology and Biotechnology, vol. 52, no. 2, pp. 149-156, 1991.

[7] D. Sarkar, M. Ferguson, R. Datta, and S. Birnbaum, "Bioremediation of petroleum hydrocarbons in contaminated soils: comparison of biosolids addition, carbon supplementation, and monitored natural attenuation," Environmental Pollution, vol. 136, no. 1, pp. 187-195, 2005.

[8] P. Fernández-Álvarez, J. Vila, J. M. Garrido-Fernández, M. Grifoll, and J. M. Lema, "Trials of bioremediation on a beach affected by the heavy oil spill of the Prestige," Journal of Hazardous Materials, vol. 137, no. 3, pp. 1523-1531, 2006.

[9] N. Kosaric, "Biosurfactants and their application for soil bioremediation," Food Technology and Biotechnology, vol. 39, no. 4, pp. 295-304, 2001.

[10] E. Z. Ron and E. Rosenberg, "Biosurfactants and oil bioremediation," Current Opinion in Biotechnology, vol. 13, no. 3, pp. 249-252, 2002.

[11] S. S. Cameotra and P. Singh, "Bioremediation of oil sludge using crude biosurfactants," International Biodeterioration and Biodegradation, vol. 62, no. 3, pp. 274-280, 2008.

[12] I. M. Banat, A. Franzetti, I. Gandolfi et al., "Microbial biosurfactants production, applications and future potential,"
Applied Microbiology and Biotechnology, vol. 87, no. 2, pp. 427444, 2010.

[13] P. V. O. Trindade, L. G. Sobral, A. C. L. Rizzo, S. G. F. Leite, and A. U. Soriano, "Bioremediation of a weathered and a recently oil-contaminated soils from Brazil: a comparison study," Chemosphere, vol. 58, no. 4, pp. 515-522, 2005.

[14] F. Beolchini, L. Rocchetti, and A. Dell'Anno, "Kinetic modeling of bioremediation processes applied to marine sediments," Chemical Engineering Transactions, vol. 24, pp. 1039-1044, 2011.

[15] K. T. Semple, B. J. Reid, and T. R. Fermor, "Impact of composting strategies on the treatment of soils contaminated with organic pollutants," Environmental Pollution, vol. 112, no. 2, pp. 269-283, 2001.

[16] H. Yu, G. H. Huang, C. J. An, and J. Wei, "Combined effects of DOM extracted from site soil/compost and biosurfactant on the sorption and desorption of PAHs in a soil-water system," Journal of Hazardous Materials, vol. 190, no. 1-3, pp. 883-890, 2011.

[17] J. D. Coates, R. T. Anderson, J. C. Woodward, E. J. P. Phillips, and D. R. Lovley, "Anaerobic hydrocarbon degradation in petroleum-contaminated harbor sediments under sulfatereducing and artificially imposed iron-reducing conditions," Environmental Science and Technology, vol. 30, no. 9, pp. 27842789, 1996.

[18] R. Boopathy, "Use of anaerobic soil slurry reactors for the removal of petroleum hydrocarbons in soil," International Biodeterioration and Biodegradation, vol. 52, no. 3, pp. 161166, 2003.

[19] F. Widdel and R. Rabus, "Anaerobic biodegradation of saturated and aromatic hydrocarbons," Current Opinion in Biotechnology, vol. 12, no. 3, pp. 259-276, 2001.

[20] R. P. J. Swannell, K. Lee, and M. Mcdonagh, "Field evaluations of marine oil spill bioremediation," Microbiological Reviews, vol. 60, no. 2, pp. 342-365, 1996.

[21] I. M. Head and R. P. J. Swannell, "Bioremediation of petroleum hydrocarbon contaminants in marine habitats," Current Opinion in Biotechnology, vol. 10, no. 3, pp. 234-239, 1999.

[22] R. Xu, A. N. L. Lau, Y. G. Lim, and J. P. Obbard, "Bioremediation of oil-contaminated sediments on an inter-tidal shoreline using a slow-release fertilizer and chitosan," Marine Pollution Bulletin, vol. 51, no. 8-12, pp. 1062-1070, 2005.

[23] F. Beolchini, L. Rocchetti, F. Regoli, and A. Dell'Anno, "Bioremediation of marine sediments contaminated by hydrocarbons: experimental analysis and kinetic modeling," Journal of Hazardous Materials, vol. 182, no. 1-3, pp. 403-407, 2010.

[24] G. Miralles, V. Grossi, M. Acquaviva, R. Duran, J. C. Bertrand, and P. Cuny, "Alkane biodegradation and dynamics of phylogenetic subgroups of sulfate-reducing bacteria in an anoxic coastal marine sediment artificially contaminated with oil," Chemosphere, vol. 68, no. 7, pp. 1327-1334, 2007.

[25] B. V. Chang, L. C. Shiung, and S. Y. Yuan, "Anaerobic biodegradation of polycyclic aromatic hydrocarbon in soil," Chemosphere, vol. 48, no. 7, pp. 717-724, 2002.

[26] S. A. Pombo, J. Kleikemper, M. H. Schroth, and J. Zeyer, "Field-scale isotopic labeling of phospholipid fatty acids from acetate-degrading sulfate-reducing bacteria," FEMS Microbiology Ecology, vol. 51, no. 2, pp. 197-207, 2005.

[27] J. Gao, R. S. Skeen, B. S. Hooker, and R. D. Quesenberry, "Effects of several electron donors on tetrachloroethylene dechlorination in anaerobic soil microcosms," Water Research, vol. 31, no. 10, pp. 2479-2486, 1997. 
[28] K. Ingvorsen, M. Y. Nielsen, and C. Joulian, "Kinetics of bacterial sulfate reduction in an activated sludge plant," FEMS Microbiology Ecology, vol. 46, no. 2, pp. 129-137, 2003.

[29] R. Danovaro, E. Manini, and A. Dell'Anno, "Higher abundance of bacteria than of viruses in deep Mediterranean sediments," Applied and Environmental Microbiology, vol. 68, no. 3, pp. 1468-1472, 2002.

[30] B. Scaglia, F. G. Erriquens, G. Gigliotti et al., "Precision determination for the specific oxygen uptake rate (SOUR) method used for biological stability evaluation of compost and biostabilized products," Bioresource Technology, vol. 98, no. 3, pp. 706-713, 2007.

[31] M. Ritzkowski, K. U. Heyer, and R. Stegmann, "Fundamental processes and implications during in situ aeration of old landfills," Waste Management, vol. 26, no. 4, pp. 356-372, 2006.

[32] F. M. Bento, F. A. O. Camargo, B. C. Okeke, and W. T. Frankenberger, "Comparative bioremediation of soils contaminated with diesel oil by natural attenuation, biostimulation and bioaugmentation," Bioresource Technology, vol. 96, no. 9, pp. 1049-1055, 2005.

[33] L. Tsui and W. R. Roy, "Effect of compost age and composition on the atrazine removal from solution," Journal of Hazardous Materials, vol. B139, no. 1, pp. 79-85, 2007.

[34] R. van Herwijnen, D. Springael, P. Slot, H. A. J. Govers, and J. R. Parsons, "Degradation of anthracene by Mycobacterium sp. strain LB501T proceeds via a novel pathway, through ophthalic acid," Applied and Environmental Microbiology, vol. 69, no. 1, pp. 186-190, 2003.

[35] J. Heider, A. M. Spormann, H. R. Beller, and F. Widdel, "Anaerobic bacterial metabolism of hydrocarbons," FEMS Microbiology Reviews, vol. 22, no. 5, pp. 459-473, 1999.

[36] V. G. Grishchenkov, R. T. Townsend, T. J. McDonald, R. L. Autenrieth, J. S. Bonner, and A. M. Boronin, "Degradation of petroleum hydrocarbons by facultative anaerobic bacteria under aerobic and anaerobic conditions," Process Biochemistry, vol. 35, no. 9, pp. 889-896, 2000.

[37] J. M. Salminen, P. M. Tuomi, A. M. Suortti, and K. S. Jørgensen, "Potential for aerobic and anaerobic biodegradation of petroleum hydrocarbons in boreal subsurface," Biodegradation, vol. 15, no. 1, pp. 29-39, 2004.

[38] D. C. Montgomery, Design and Analysis of Experiments, Wiley, New York, NY, USA, 3rd edition, 1991.

[39] A. Dell'Anno, F. Beolchini, M. Gabellini, L. Rocchetti, A. Pusceddu, and R. Danovaro, "Bioremediation of petroleum hydrocarbons in anoxic marine sediments: consequences on the speciation of heavy metals," Marine Pollution Bulletin, vol. 58, no. 12, pp. 1808-1814, 2009. 

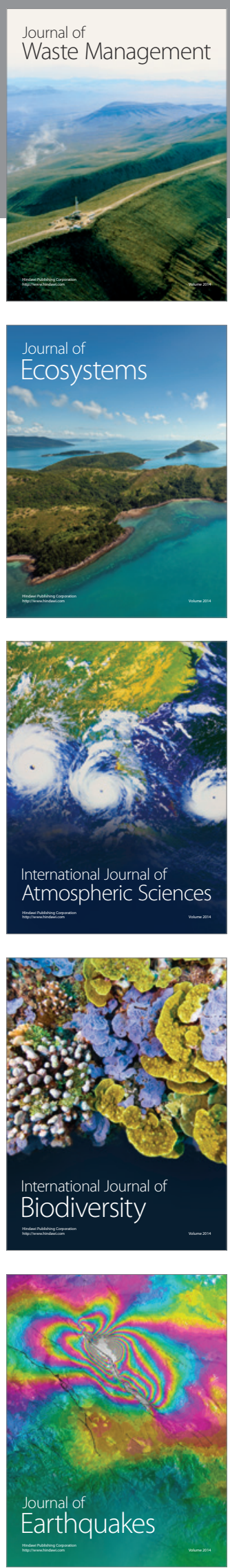
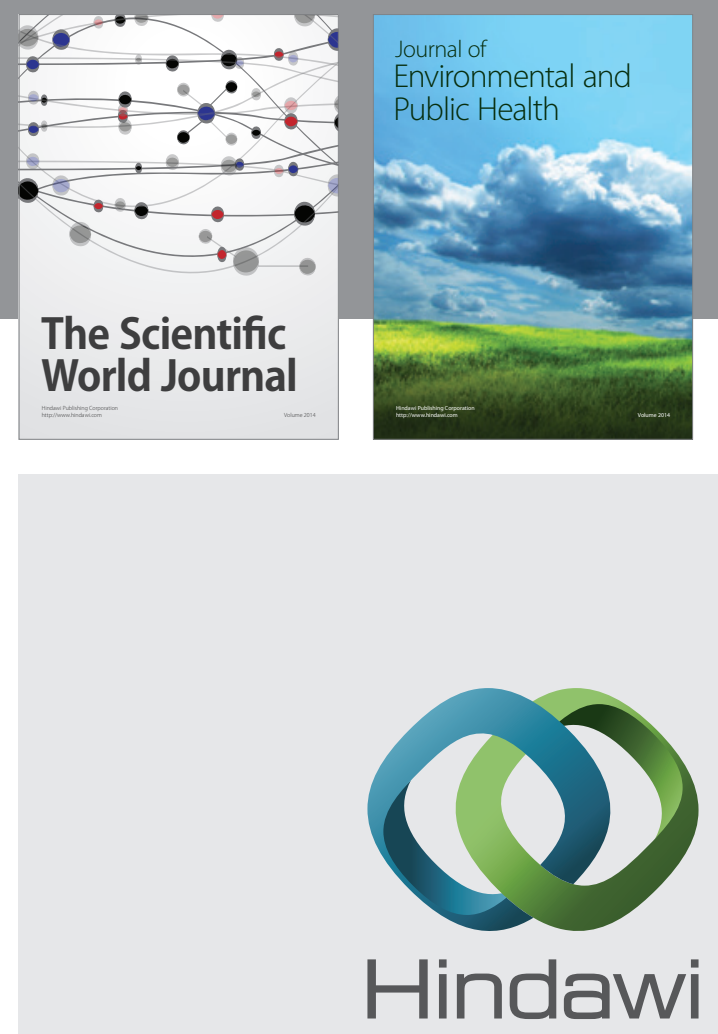

Submit your manuscripts at

http://www.hindawi.com
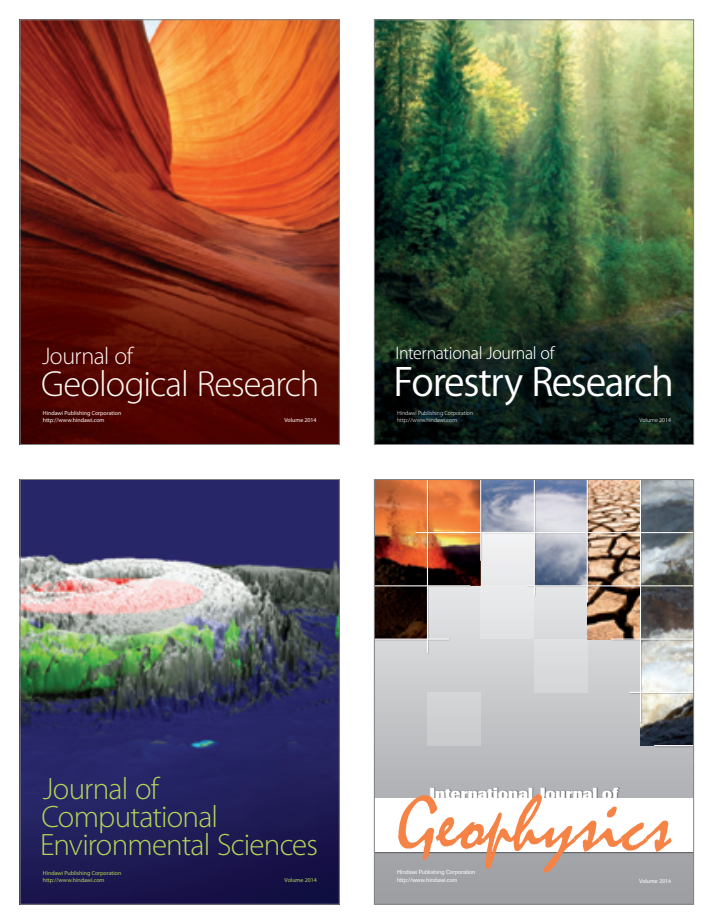
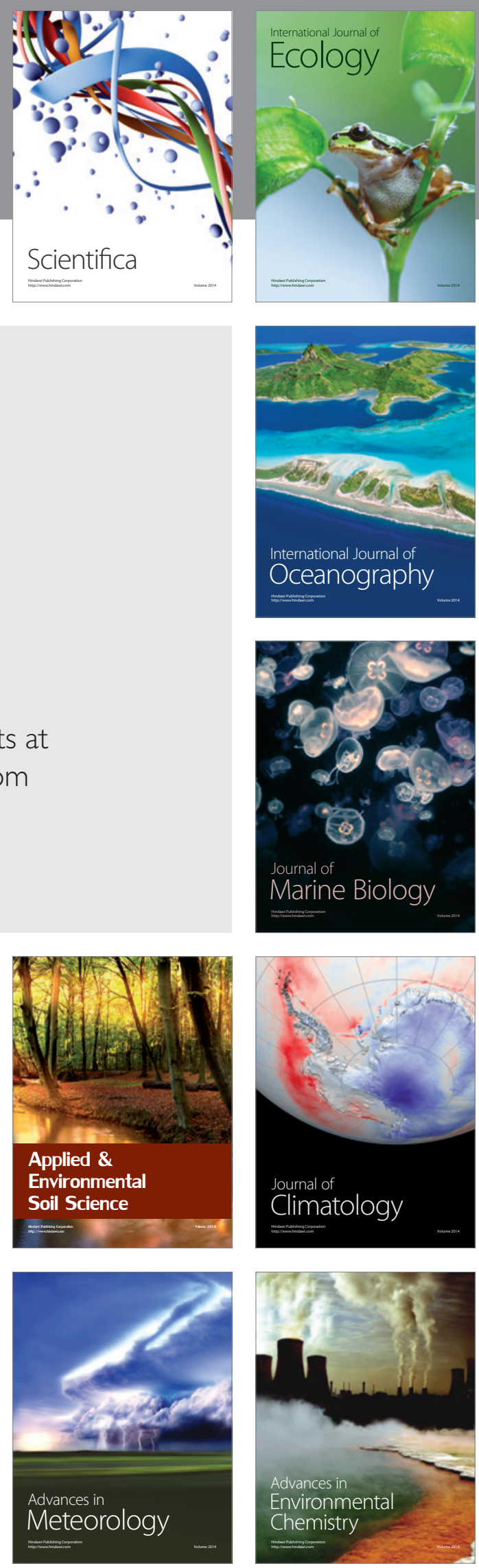